\title{
Influence of Annealing Temperature on the Magnetic Properties of Rapidly Quenched $(\mathrm{Nd}, \mathrm{Pr})_{2}-(\mathrm{Fe}, \mathrm{Co}, \mathrm{Ga}, \mathrm{Ti}, \mathrm{C})_{14} \mathrm{~B} / \alpha-\mathrm{Fe}$ Nanocomposite Ribbons
}

\author{
Rahim Sabbaghizadeh, ${ }^{1}$ Mansor Hashim, ${ }^{2}$ Reza Gholamipour, ${ }^{3}$ \\ Ghazaleh Bahmanrokh, ${ }^{1}$ and Mohd Shamsul Ezzad Shafie ${ }^{1}$ \\ ${ }^{1}$ Advanced Material and Nanotechnology Laboratory, Institute of Advanced Technology (ITMA), Universiti Putra Malaysia, \\ UPM Serdang 43400, Selangor, Malaysia \\ ${ }^{2}$ Physics Department, Faculty of Science, Universiti Putra Malaysia, Serdang 43400, Selangor, Malaysia \\ ${ }^{3}$ Advanced Materials and Renewal Energy Department, Iran Research Organization for Science and Technology (IROST), Tehran, Iran
}

Correspondence should be addressed to Rahim Sabbaghizadeh; r.h.sabba@gmail.com

Received 26 September 2013; Accepted 8 November 2013

Academic Editor: Luís Cunha

Copyright (C) 2013 Rahim Sabbaghizadeh et al. This is an open access article distributed under the Creative Commons Attribution License, which permits unrestricted use, distribution, and reproduction in any medium, provided the original work is properly cited.

\begin{abstract}
The effects of different heat treatment temperatures on the structure and magnetic properties of Nd-Fe- $\mathrm{B}$ nanocomposite permanent magnetic alloys with nominal composition of $\mathrm{Nd}_{9.4} \mathrm{Pr}_{0.6} \mathrm{Fe}_{74.5} \mathrm{Co}_{6} \mathrm{~B}_{6} \mathrm{Ga}_{0.5} \mathrm{Ti}_{1.5} \mathrm{C}_{1.5}$ have been investigated. The most practical method to produce nanostructured metallic materials is rapid solidification. Melt spinning with constant wheel speed of $V=40 \mathrm{~m} / \mathrm{s}$ was employed to produce ribbons. As-spun ribbons were examined by using differential scanning calorimetry (DSC) and Xray diffractometer (XRD) with $\mathrm{Cu}-\mathrm{k} \alpha$ radiation. The ribbons were annealed at different temperatures in order to extract the best magnetic properties. The XRD and electron microscopy technique results confirm that grains are in the size of less than $50 \mathrm{~nm}$. In addition, optimum magnetic properties were obtained at $700^{\circ} \mathrm{C}$ annealed temperature.
\end{abstract}

\section{Introduction}

Recently, considerable attention has been focused on the magnetic properties of nanostructured $\mathrm{Nd}-\mathrm{Fe}-\mathrm{B}$ magnet alloy, which has been prepared by the recrystallization of either melt-spun or mechanically alloyed materials, because of their technological properties and unusual scientific behavior [1-6]. Neodymium-iron-boron nanocomposite magnets consist of a soft magnetic phase $\left(\alpha-\mathrm{Fe}_{\mathrm{f}}\right.$ or $\left.\mathrm{Fe}_{3} \mathrm{~b}\right)$ and a hard magnetic phase $\left(\mathrm{Nd}_{2} \mathrm{Fe}_{14} \mathrm{~B}\right)$. In these materials the soft magnetic phase has higher inherent magnetization, and the hard magnetic phase has a higher anisotropy constant and higher remanence; therefore, higher energy product will be achieved in comparison with single phase material because of exchange coupling between the magnetically soft and hard phases. In addition, a smaller amount of rare earth elements are required $[7,8]$. The nanocomposite produced by crystallization of amorphous phase into a mixture of hard and soft phases mainly $\mathrm{Nd}_{2} \mathrm{Fe}_{14} \mathrm{~B} / \alpha$-Fe. Usually $\alpha$-Fe tends to grow during annealing and precipitates sooner than $\mathrm{Nd}_{2} \mathrm{Fe}_{14} \mathrm{~B}$. It is plainly visible that a uniform distribution of fine grains is essential for obtaining effective exchange coupling [9]. Fischer et al. proposed that an optimum microstructure consists of small soft magnetic grains with sizes of about $10 \mathrm{~nm}$ and hard magnetic grains with a mean grain diameter of about $20 \mathrm{~nm}$ [3]. In order to achieve a significant enhancement of remanence polarisation $\left(J_{r}\right)$ and to preserve a high intrinsic coercivity in isotropic nanocrystalline $\mathrm{Nd}_{2} \mathrm{Fe}_{14} \mathrm{~B}$-based magnets, a mean grain size of less than $20 \mathrm{~nm}$ is required [10]. Furthermore, it was found that the size and volume fraction of $\alpha$-Fe and $\mathrm{Nd}_{2} \mathrm{Fe}_{14} \mathrm{~B}$ can be manipulated by thermal processing and by elemental substitution, 


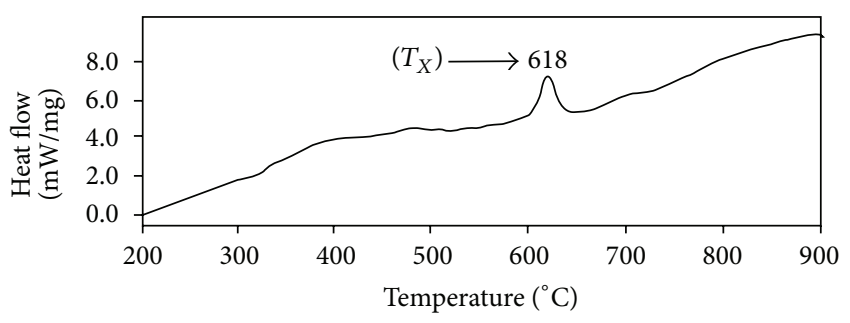

Figure 1: DSC scans of $\mathrm{Nd}_{9.4} \mathrm{Pr}_{0.6} \mathrm{Fe}_{74.5} \mathrm{Co}_{6} \mathrm{~B}_{6} \mathrm{Ga}_{0.5} \mathrm{Ti}_{1.5} \mathrm{C}_{1.5}$.

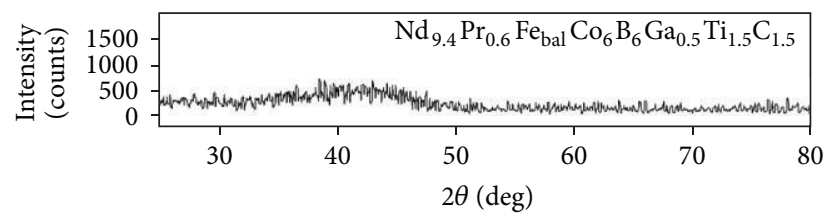

FIGURE 2: X-ray diffraction patterns of as-spun ribbon.

leading to the increase of the magnetic properties, for example, $\mathrm{Br}$ and $(\mathrm{BH})_{\max }$ of the fully processed materials [6]. In recent years various investigations have been carried out in order to increase magnetic properties by changing the heat treatment parameters. In this research effect of heat treatment on the structure and magnetic properties of melt-spun $\mathrm{Nd}_{9.4} \mathrm{Pr}_{0.6} \mathrm{Fe}_{74.5} \mathrm{Co}_{6} \mathrm{~B}_{6} \mathrm{Ga}_{0.5} \mathrm{Ti}_{1.5} \mathrm{C}_{1.5}$ has been investigated.

\section{Experimental Procedure}

An alloy with the nominal composition of $\mathrm{Nd}_{9.4} \mathrm{Pr}_{0.6} \mathrm{Fe}_{74.5} \mathrm{Co}_{6} \mathrm{~B}_{6} \mathrm{Ga}_{0.5} \mathrm{Ti}_{1.5} \mathrm{C}_{1.5}$ was prepared by the vacuum arc melting (VAR) method under purified $\mathrm{Ar}$ atmosphere. The ingot was produced by this method remelted for four times in order to get the homogeneity. The melt spinning method was used to produce amorphous ribbons in the nanometer scale by a constant wheel speed of $v=40 \mathrm{~m} / \mathrm{s}$. The chamber Ar pressure was $930 \mathrm{mbar}$ and the ejection pressure was 0.3 bar, and the orifice diameter of quartz tube was $0.5 \mathrm{~mm}$. The as-spun ribbon was sealed in a quartz tube under $4.5 \times 10^{-4}$ mbar vacuum, after that annealed at four different temperatures $\left(600^{\circ} \mathrm{C}, 650^{\circ} \mathrm{C}\right.$, $700^{\circ} \mathrm{C}$, and $750^{\circ} \mathrm{C}$ ) for 10 minutes, and then cooled in water. The structure of the ribbons was preliminarily examined using X-ray diffraction (XRD) with monochromatic $\mathrm{Cu}$ $\mathrm{K} \alpha$ radiation before and after annealing. Crystallization evolution and determination of crystallization temperature of the as-cast sample were monitored using differential scanning calorimetry (DSC) on SDT 2960 TA instruments in an $\mathrm{Ar}$ atmosphere. Demagnetization curves were measured by using a vibrating sample magnetometer (VSM) after magnetizing the ribbons with a pulsed magnetic field of at least $1.5 \mathrm{~T}$.

\section{Results and Discussion}

Figure 1 shows the DSC traces for crystallization of $\mathrm{Nd}_{9.4} \mathrm{Pr}_{0.6} \mathrm{Fe}_{74.5} \mathrm{Co}_{6} \mathrm{~B}_{6} \mathrm{Ga}_{0.5} \mathrm{Ti}_{1.5} \mathrm{C}_{1.5}$ alloy. It is noticeable

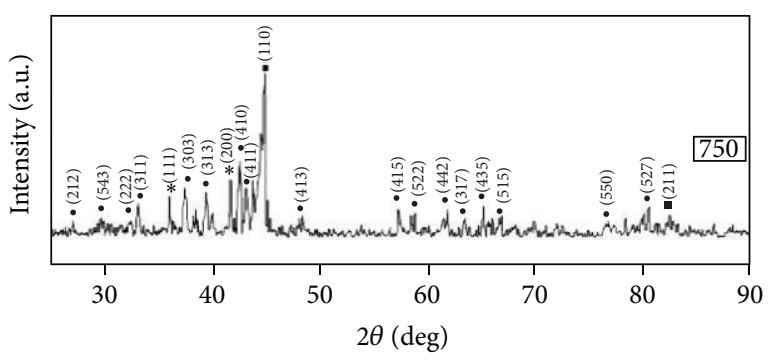

(a)

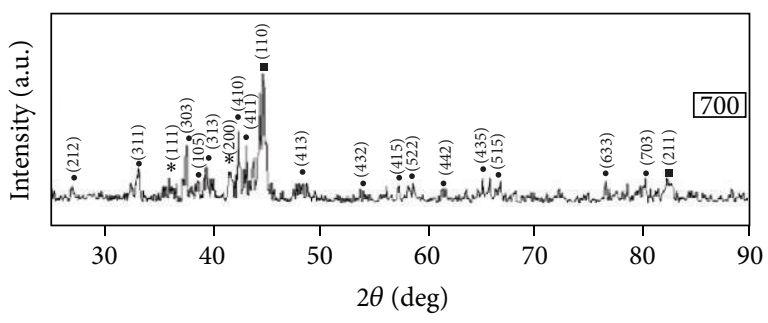

(b)

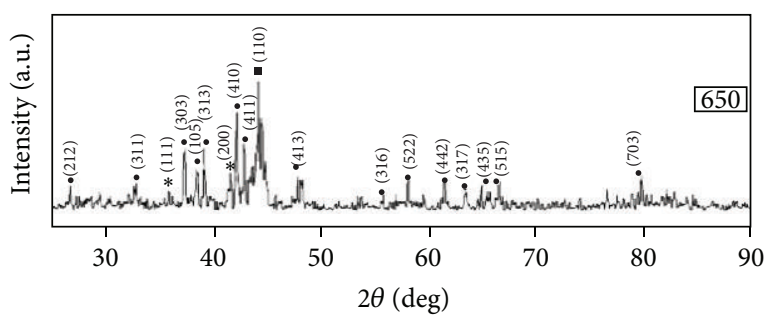

(c)

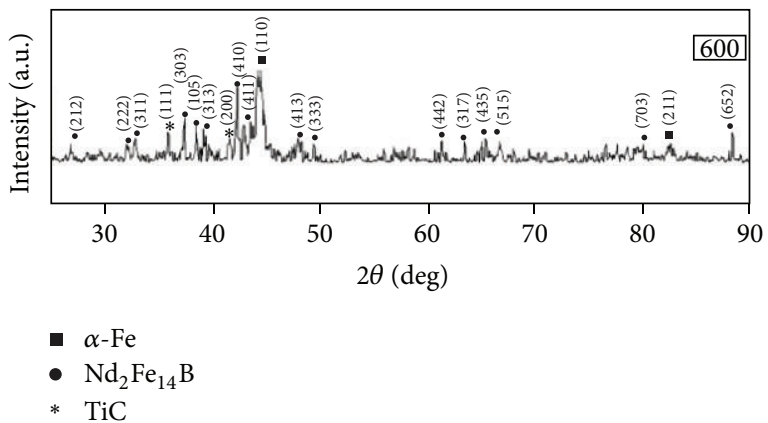

(d)

FIGURE 3: XRD patterns of $\mathrm{Nd}_{9.4} \mathrm{Pr}_{0.6} \mathrm{Fe}_{74.5} \mathrm{Co}_{6} \mathrm{~B}_{6} \mathrm{Ga}_{0.5} \mathrm{Ti}_{1.5} \mathrm{C}_{1.5}$ ribbon after thermal treatment at different temperature for 10 minutes.

that there is only one exothermic peak which means that the prior precipitation of $\alpha$-Fe was inhibited and crystallization of both $\alpha$-Fe and $\mathrm{Nd}_{2} \mathrm{Fe}_{14} \mathrm{~B}$ occurs simultaneously. Powder $\mathrm{X}$-ray diffraction patterns of asquenched $\mathrm{Nd}_{9.4} \mathrm{Pr}_{0.6} \mathrm{Fe}_{74.5} \mathrm{Co}_{6} \mathrm{~B}_{6} \mathrm{Ga}_{0.5} \mathrm{Ti}_{1.5} \mathrm{C}_{1.5}$ ribbons are shown in Figure 2. The XRD scans of the as-spun ribbons can be used to qualitatively estimate the amount of glass formation [6]. As it was mentioned before the wheel speed is constant and because of the straight relation between cooling rate and wheel speed it can be concluded that the cooling rate in our experiment is constant so the formation of amorphous structures is due to change of critical cooling rate necessary 


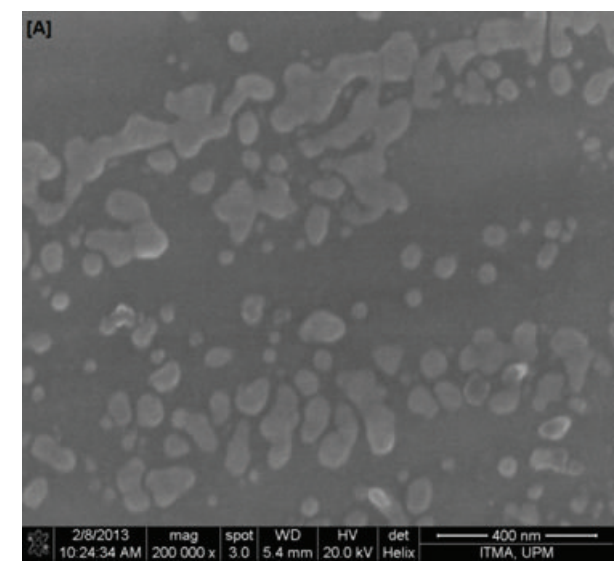

(a)

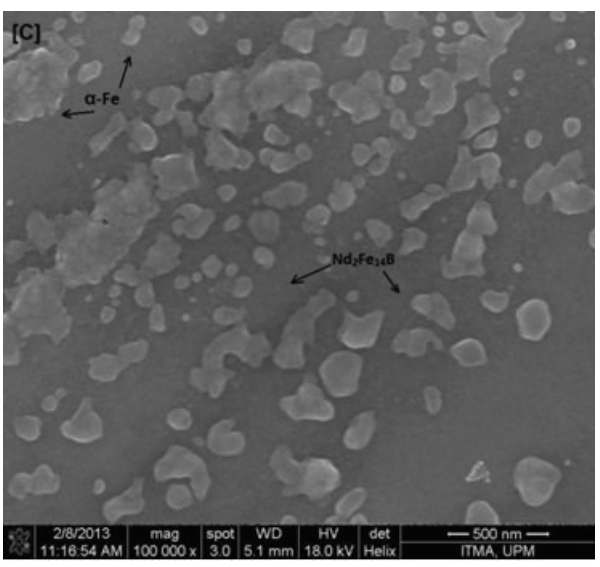

(c)

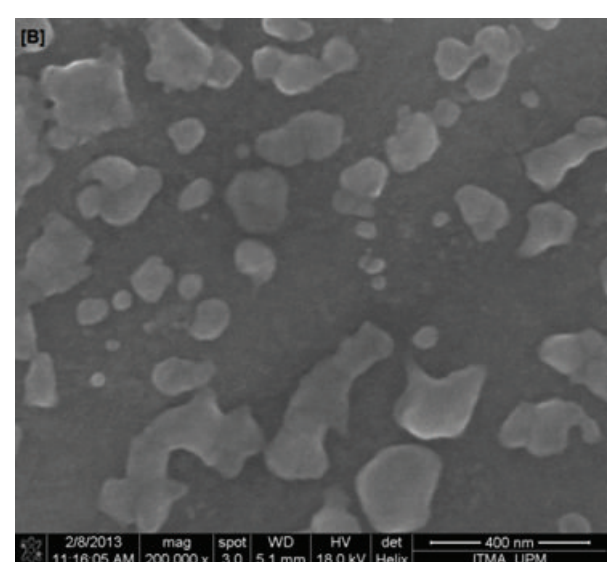

(b)

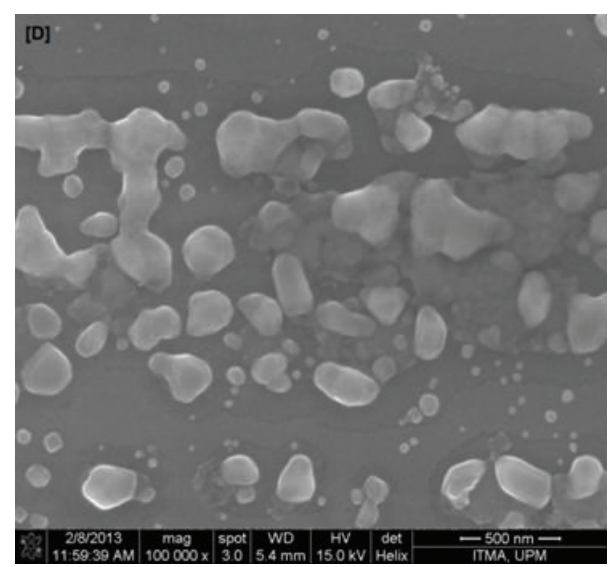

(d)

FIGURE 4: FESEM morphologies of $\mathrm{Nd}_{9.4} \mathrm{Pr}_{0.6} \mathrm{Fe}_{74.5} \mathrm{Co}_{6} \mathrm{~B}_{6} \mathrm{Ga}_{0.5} \mathrm{Ti}_{1.5} \mathrm{C}_{1.5}$ at (a) $600^{\circ} \mathrm{C}$, (b) $650^{\circ} \mathrm{C}$, (c) $700^{\circ} \mathrm{C}$, and (d) $750^{\circ} \mathrm{C}$ annealed ribbons for 10 minutes.

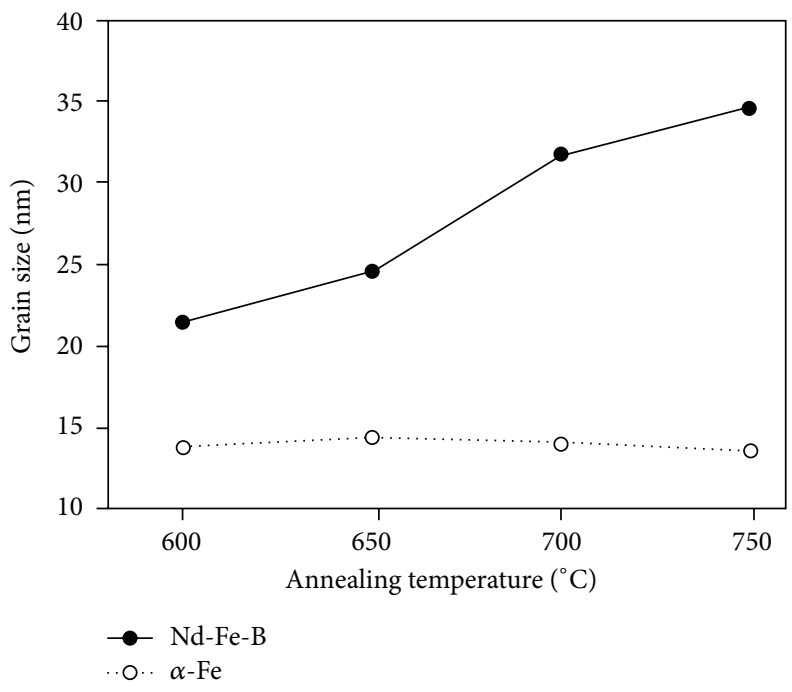

FIGURE 5: Grain sizes of $\mathrm{Nd}_{9.4} \mathrm{Pr}_{0.6} \mathrm{Fe}_{74.5} \mathrm{Co}_{6} \mathrm{~B}_{6} \mathrm{Ga}_{0.5} \mathrm{Ti}_{1.5} \mathrm{C}_{1.5}$ annealed ribbon at different annealing temperature for 10 minutes. 


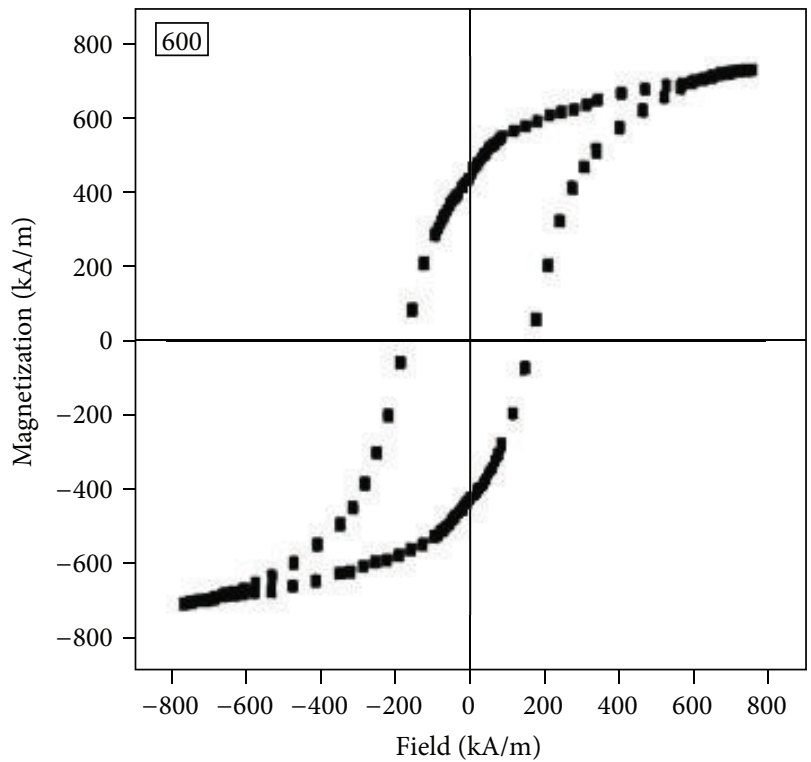

(a)

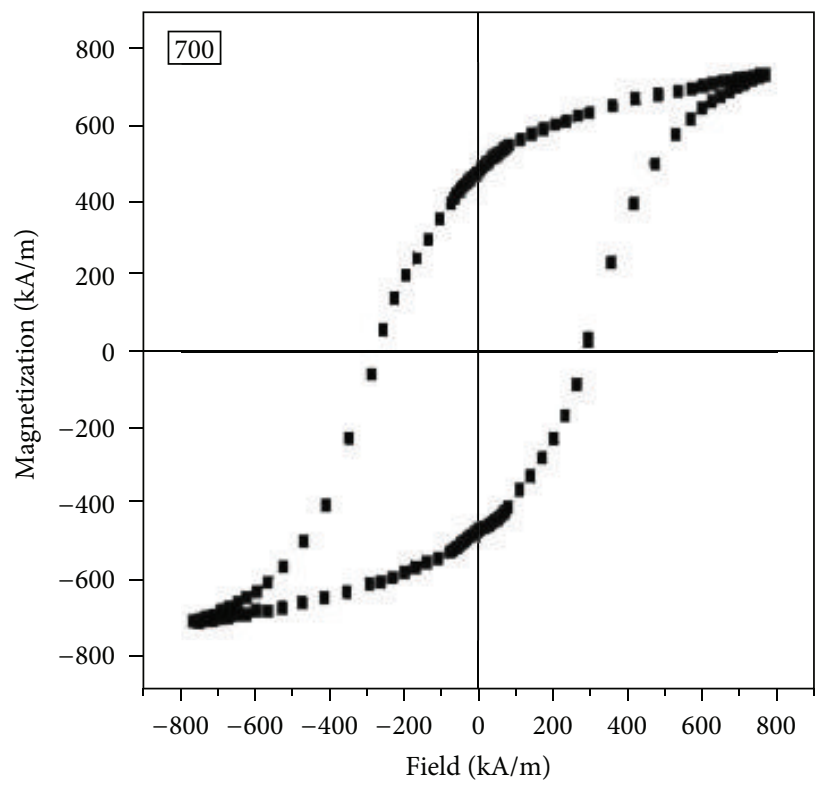

(c)

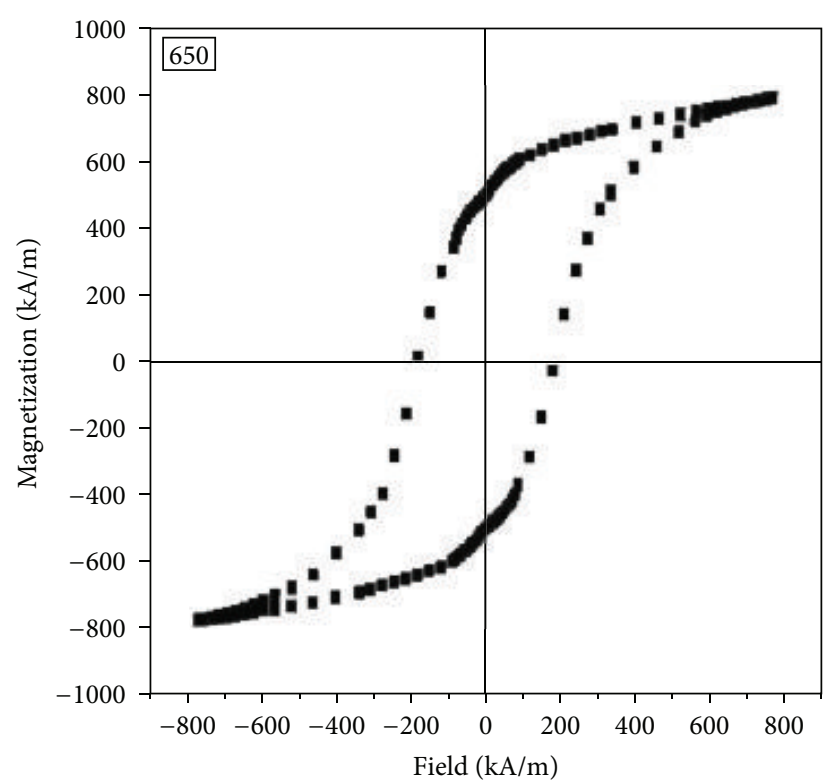

(b)

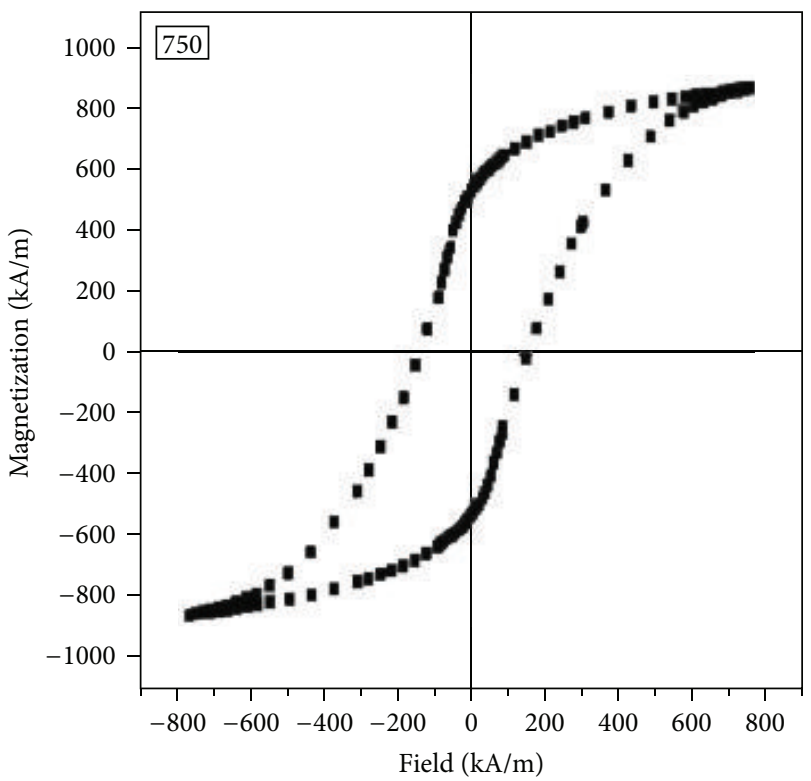

(d)

Figure 6: Hysteresis loops of $\mathrm{Nd}_{9.4} \mathrm{Pr}_{0.6} \mathrm{Fe}_{74.5} \mathrm{Co}_{6} \mathrm{~B}_{6} \mathrm{Ga}_{0.5} \mathrm{Ti}_{1.5} \mathrm{C}_{1.5}$ annealed ribbon at different annealing temperature for 10 minutes.

to form an amorphous structure from the melt. The XRD pattern of ribbons after a thermal treatment from $600^{\circ} \mathrm{C}$ to $750^{\circ} \mathrm{C}$ is shown in Figure 3. It can be seen that the annealed samples consist of a hard magnetic $\mathrm{Nd}_{2} \mathrm{Fe}_{14} \mathrm{~B}$ phase and soft magnetic $\alpha$-Fe phase and TiC phase have precipitated as well as the hard and soft magnetic phases. It was found that the amounts of soft and hard phases are increased with increasing temperature, suggesting that the enhancement of crystallinity was due to the heat treatment. Figure 4 shows the surface microstructure of annealed samples. As can be seen, the darker parts of the micrographs are $\mathrm{Nd}_{2} \mathrm{Fe}_{14} \mathrm{~B}$ and the lighter parts are related to $\alpha$-Fe phase. Obviously, the micrographs indicate that grain growth is occurring. The average grain size of a sintered body was measured over 200 grains by the linear intercept method. The results are shown in Figure 5; the $\alpha$-Fe grains have not been changed significantly during annealing, except the slight increase and decrease, which are related to the experimental errors with size of \pm 2 nanometer. Thus, heat treatment has not any effect on grain growth of the soft magnetic phase; on the other hand the Nd-Fe-B grain size increases with the increase of the heat treatment temperature. Magnetic properties of annealed ribbons were measured by alternate gradient force magnetometer (AGFM) with maximum applied field of 1.5 Tesla. The hysteresis 
TABLE 1: Magnetic properties of annealed ribbon at different annealing temperature for 10 minutes.

\begin{tabular}{lcccc}
\hline Composition & Annealing temperature $(\mathrm{K})$ & $J_{r} / J_{s}$ & $\mathrm{Hc}\left(\mathrm{KA} \mathrm{m}^{-1}\right)$ & $\left(\mathrm{BH}_{\max }\right)\left(\mathrm{KJ} / \mathrm{m}^{3}\right)$ \\
\hline & 600 & 0.58 & 202 & 36.70 \\
$\mathrm{Nd}_{9.4} \mathrm{Pr}_{0.6} \mathrm{Fe}_{74.5} \mathrm{Co}_{6} \mathrm{~B}_{6} \mathrm{Ga}_{0.5} \mathrm{Ti}_{1.5} \mathrm{C}_{1.5}$ & 650 & 0.61 & 233 & 48.15 \\
& 700 & 0.64 & 245 & 60.48 \\
& 750 & 0.57 & 177 & 28.50 \\
\hline
\end{tabular}

loop results are illustrated in Figure 6, the calculated data are summarized in Table 1, and Figure 5 demonstrates the dependence of magnetic properties on the temperature of annealing. As can be seen magnetic properties of the composition differ by changing the annealing temperature; for $\mathrm{Nd}_{9.4} \mathrm{Pr}_{0.6} \mathrm{Fe}_{74.5} \mathrm{Co}_{6} \mathrm{~B}_{6} \mathrm{Ga}_{0.5} \mathrm{Ti}_{1.5} \mathrm{C}_{1.5}$ annealed ribbons the best magnetic properties achieve at $700^{\circ} \mathrm{C}$. Generally, the grain growth which occurs at the higher temperatures leads to deterioration in the magnetic properties [11]; hence, heat treatment at $750^{\circ} \mathrm{C}$ leads to inferior properties than those for $700^{\circ} \mathrm{C}$ annealing temperature. Furthermore, the $J_{r} / J_{s}$ values are close to one another due to soft phase's grain size similarity [12]. The maximum energy product $\left(\mathrm{BH}_{\max }\right)$, which is sensitive to exchange coupling and grain size, was enhanced with anneals temperature increases until $700^{\circ} \mathrm{C}$ due to more suitable exchange coupling at higher temperatures [13]. But after $700^{\circ} \mathrm{C}$ decreases because of hard phase extra grain growth, the maximum energy product $\left(\mathrm{BH}_{\max }\right)$ of the nanocomposite magnets depends sensitively on the form of nanostructure, for example, phases present, crystallite size, and defects present [14]. However, this is not the whole story since, in comparing the ribbons with the same composition, the $700^{\circ} \mathrm{C}$ annealed ribbon has improved maximum energy product $\left(\mathrm{BH}_{\max }\right)$, due to more uniform grain size distribution and higher quality crystalline $\mathrm{Nd}_{2} \mathrm{Fe}_{14} \mathrm{~B}$ grains. The coercivity of the ribbons increased to $700^{\circ} \mathrm{C}$, and then it decreased due to optimum exchange coupling at $700^{\circ} \mathrm{C}$, leading the best coercivity at this temperature.

\section{Conclusion}

The relationship between annealing temperature, microstructure and magnetic properties of $\mathrm{Nd}_{9.4} \mathrm{Pr}_{0.6} \mathrm{Fe}_{74.5} \mathrm{Co}_{6} \mathrm{~B}_{6} \mathrm{Ga}_{0.5} \mathrm{Ti}_{1.5} \mathrm{C}_{1.5}$ nanocomposite alloys was interpreted by XRD, DSC, and FESEM analysis. It has been generally found that the crystallization behaviour of amorphous $\mathrm{Nd}_{9.4} \mathrm{Pr}_{0.6} \mathrm{Fe}_{74.5} \mathrm{Co}_{6} \mathrm{~B}_{6} \mathrm{Ga}_{0.5} \mathrm{Ti}_{1.5} \mathrm{C}_{1.5}$ alloy strongly depends on the heat treatment temperature. Additionally, it has been found that increase of annealing temperature leads to grow of $\mathrm{Nd}-\mathrm{Fe}-\mathrm{B}$ grains but does not have any effect on $\alpha$-Fe grain size. It is plainly visible that magnetic properties increase significantly with heating rate up to $700^{\circ} \mathrm{C}$ and then will decrease. The best magnetic properties were obtained at $700^{\circ} \mathrm{C}$ annealing temperature.

\section{Acknowledgment}

The authors would like to thank Ms N. Shourcheh for valuable assistance in this work.

\section{References}

[1] G. C. Hadjipanayis and R. W. Siegel, Eds., Nanophase Materials, Synihesis-Properties-Applications, vol. 260 of NATO ASI Series, Kluwer Acedemic Press, Dordrecht, The Netherlands, 1993.

[2] G. Herzer, "Amorphous and nanocrystalline soft magnets," in Magnetic Hysteresis in Novel Magnetic Materials, G. C. Hadjipanayis, Ed., vol. 338 of NATO ASI Series, pp. 711-730, 1996.

[3] R. Fischer, T. Schrefl, H. Kronmüller, and J. Fidler, "Grainsize dependence of remanence and coercive field of isotropic nanocrystalline composite permanent magnets," Journal of Magnetism and Magnetic Materials, vol. 153, no. 1-2, pp. 35-49, 1996.

[4] G. Bate, "Magnetic recording materials," Journal of Magnetism and Magnetic Materials, vol. 100, no. 1-3, pp. 413-424, 1991.

[5] D. Lambeth, "Present status and future magnetic data storage," in Magnetic Hysteresis in Novel Magnetic Materials, G. C. Hadjipanayis, Ed., vol. 338 of NATO ASI Series, pp. 767-780, 1996.

[6] G. C. Hadjipanayis, "Nanophase hard magnets," Journal of Magnetism and Magnetic Materials, vol. 200, no. 1-3, pp. 373391, 1999.

[7] Y. Q. Wu, H. Yamamoto, and K. Hono, "Microstructural investigation on the influence of $\mathrm{V}$ in $\alpha$ - $\mathrm{Fe} / \mathrm{Nd}_{2} \mathrm{Fe}_{14} \mathrm{~B}$ nanocomposite magnet," Scripta Materialia, vol. 44, no. 10, pp. 2399-2404, 2001.

[8] M. W. Chen, A. Sakai, X. M. Wang, A. Inoue, and T. Sakurai, "Distribution of $\mathrm{Nb}$ and $\mathrm{Co}$ in an $\alpha$-Fe/ $\mathrm{Nd}_{2} \mathrm{Fe}_{14} \mathrm{~B}$-type nanocomposite," Journal of Applied Physics, vol. 88, no. 11, pp. 6928-6930, 2000.

[9] E. F. Kneller and R. Hawig, “The exchange-spring magnet: a new material principle for permanent magnets," IEEE Transactions on Magnetics, vol. 27, no. 4, pp. 3588-3560, 1991.

[10] T. Schrefl, J. Fidler, and H. Kronmiiller, "Remanence and coercivity in isotropic nanocrystalline permanent magnets," Physical Review B, vol. 49, no. 9, p. 6100, 1994.

[11] J. Jakubowicz and M. Jurczyk, "Magnetic properties of nanocomposite $\mathrm{Nd}_{2}(\mathrm{Fe}, \mathrm{Co}, \mathrm{M})_{14} \mathrm{~B} / \alpha$-Fe-bonded magnets," Journal of Alloys and Compounds, vol. 269, no. 1-2, pp. 284-287, 1998.

[12] R. Sabbaghizadeh and M. Hashim, "Effects of heat treatment on the magnetic properties of melt-spun $\mathrm{Nd}_{6} \mathrm{Pr}_{1} \mathrm{Fe}_{76} \mathrm{~B}_{12} \mathrm{Ti}_{4} \mathrm{C}_{1} \mathrm{Co}_{3}$ nanocomposite ribbons," Electronic Materials Letters, vol. 9, no. 1, pp. 115-118, 2013.

[13] R. Sabbaghizadeh, M. Hashim, and S. Moraddeh, "Dependence of microstructure and magnetic properties of (Nd,Pr)(Fe,Ti,C)-B melt-spun ribbon on quenching wheel speed," Electronic Materials Letters, vol. 9, no. 3, pp. 337-340, 2013.

[14] E. Burzo, "Permanent magnets based on R-Fe-B and R-Fe-C alloys," Reports on Progress in Physics, vol. 61, no. 9, p. 1099, 1998. 

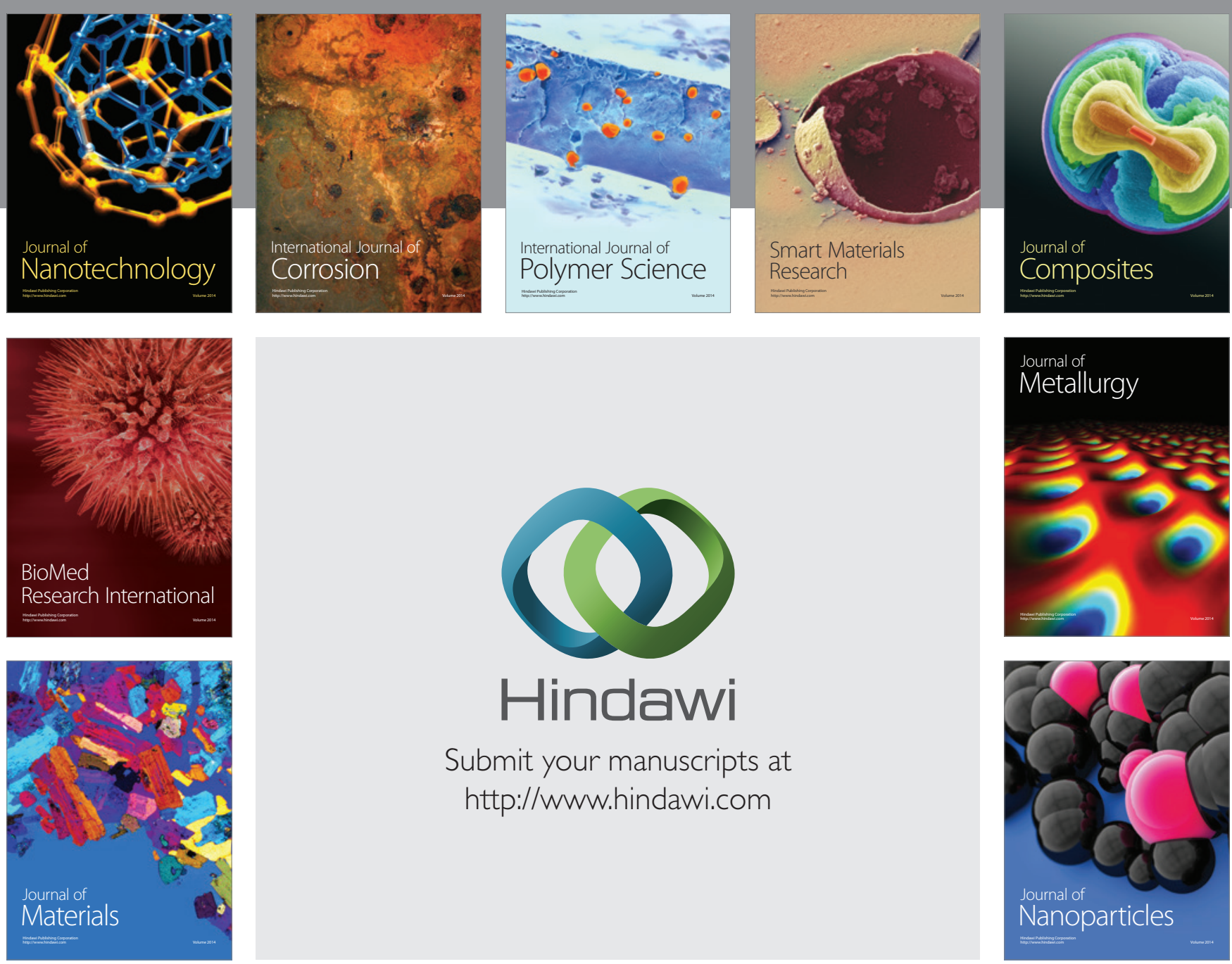

Submit your manuscripts at http://www.hindawi.com
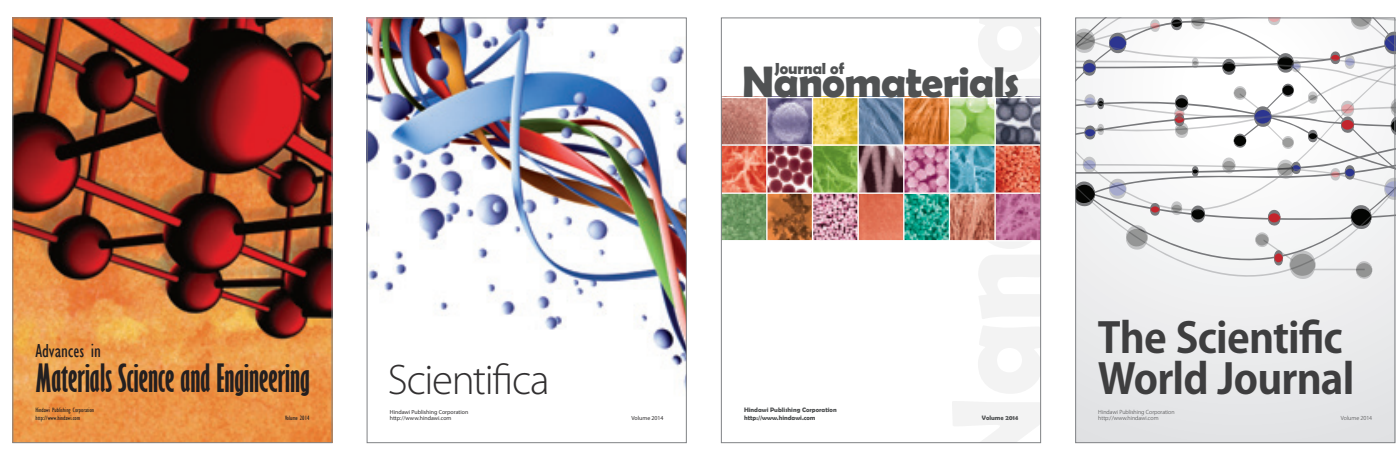

\section{The Scientific World Journal}
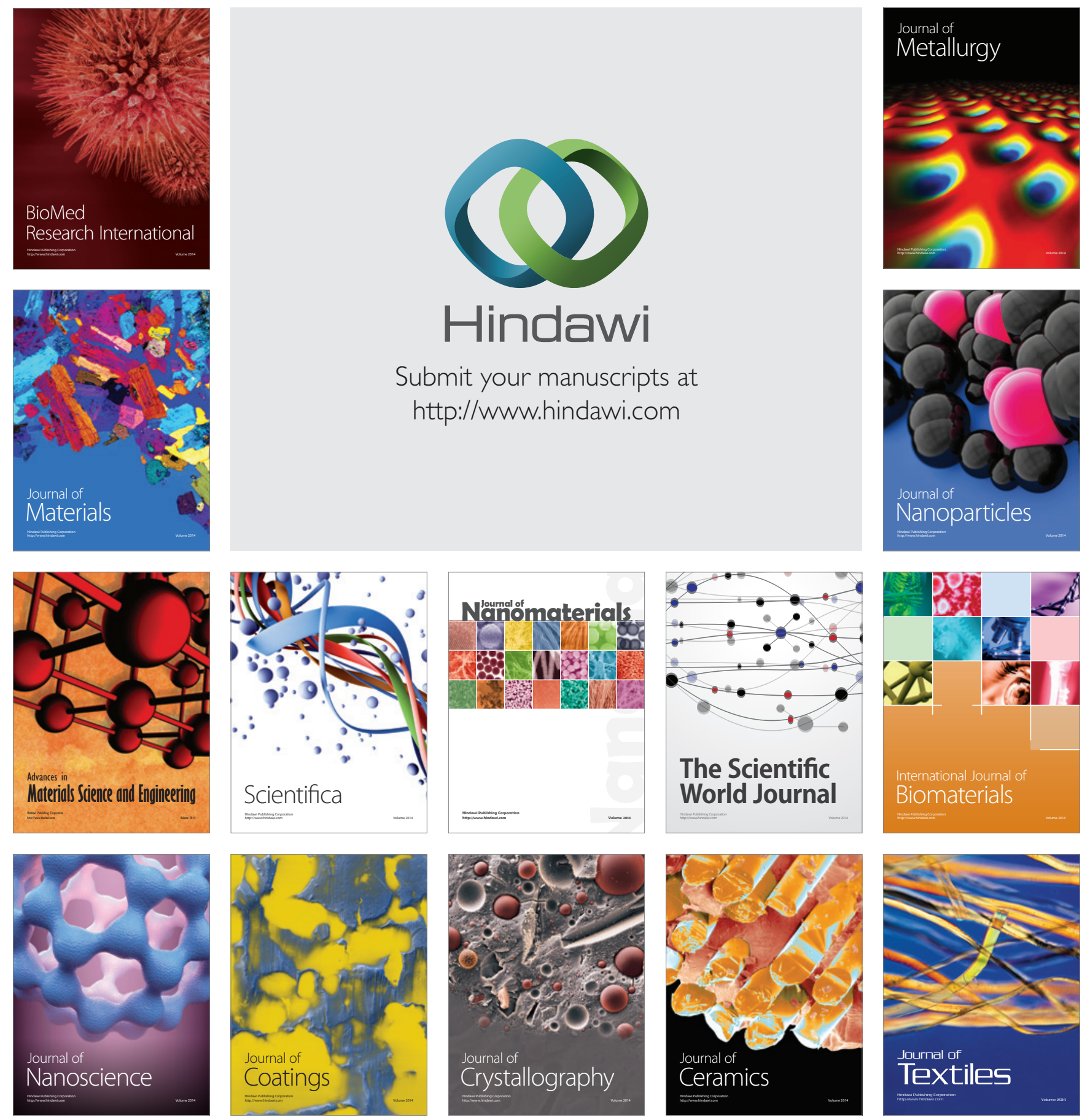